\title{
Strong convergence theorems for equilibrium problems involving a family of nonexpansive mappings
}

\section{Do D Thanh}

\section{"Correspondence:}

doduythanh.edu@gmail.com

Department of Mathematics,

Haiphong University, Haiphong,

Vietnam

\begin{abstract}
We give new hybrid variants of extragradient methods for finding a common solution of an equilibrium problem and a family of nonexpansive mappings. We present a scheme that combines the idea of an extragradient method and a successive iteration method as a hybrid variant. Then, this scheme is modified by projecting on a suitable convex set to get a better convergence property under certain assumptions in a real Hilbert space.
\end{abstract}

MSC: 65K10;65K15; 90C25; 90C33

Keywords: equilibrium problems; fixed point; pseudomonotone; Lipschitz-type continuous; extragradient method; nonexpansive mappings

\section{Introduction}

In this paper, we always assume that $\mathcal{H}$ is a real Hilbert space with the inner product $\langle\cdot, \cdot\rangle$ and the induced norm $\|\cdot\|$. Let $C$ be a nonempty closed convex subset of $\mathcal{H}$ and the bifunction $f: C \times C \rightarrow \mathcal{R}$. Then $f$ is called strongly monotone on $C$ with $\beta>0$ iff

$$
f(x, y)+f(y, x) \leq-\beta\|x-y\|^{2} \quad \forall x, y \in C ;
$$

monotone on $C$ iff

$$
f(x, y)+f(y, x) \leq 0 \quad \forall x, y \in C
$$

pseudomonotone on $C$ iff

$$
f(x, y) \geq 0 \quad \text { implies } \quad f(y, x) \leq 0 \quad \forall x, y \in C ;
$$

Lipschitz-type continuous on $C$ in the sense of Mastroeni [1] iff there exist positive constants $c_{1}>0, c_{2}>0$ such that

$$
f(x, y)+f(y, z) \geq f(x, z)-c_{1}\|x-y\|^{2}-c_{2}\|y-z\|^{2} \quad \forall x, y, z \in C .
$$

An equilibrium problem, shortly $E P(f, C)$, is to find a point in

$$
\operatorname{Sol}(f, C)=\left\{x^{*} \in C: f\left(x^{*}, y\right) \geq 0 \forall y \in C\right\} .
$$

(02014 Thanh; licensee Springer. This is an Open Access article distributed under the terms of the Creative Commons Attribution License (http://creativecommons.org/licenses/by/2.0), which permits unrestricted use, distribution, and reproduction in any medium, provided the original work is properly cited. 
Let a mapping $T$ of $C$ into itself. Then $T$ is called contractive with constant $\delta \in(0,1)$ iff

$$
\|T(x)-T(y)\| \leq \delta\|x-y\| \quad \forall x, y \in C .
$$

The mapping $T$ is called strictly pseudocontractive iff there exists a constant $k \in[0,1)$ such that

$$
\|T(x)-T(y)\|^{2} \leq\|x-y\|^{2}+k\|(I-T)(x)-(I-T)(y)\|^{2} .
$$

In the case $k=0$, the mapping $T$ is called nonexpansive on $C$. We denote by $\operatorname{Fix}(T)$ the set of fixed points of $T$.

Let $T_{i}: C \rightarrow C, i \in \Gamma$, be a family of nonexpansive mappings where $\Gamma$ stands for an index set. In this paper, we are interested in the problem of finding a common element of the solution set of problem $E P(f, C)$ and the set of fixed points $F=\bigcap_{i \in \Gamma} \operatorname{Fix}\left(T_{i}\right)$, namely:

$$
\text { Find } x^{*} \in F \cap \operatorname{Sol}(f, C) \text {, }
$$

where the function $f$ and the mappings $T_{i}, i \in \Gamma$, satisfy the following conditions:

( $\left.\mathrm{A}_{1}\right) f(x, x)=0$ for all $x \in C$ and $f$ is pseudomonotone on $C$,

$\left(\mathrm{A}_{2}\right) f$ is Lipschitz-type continuous on $C$ with constants $c_{1}>0$ and $c_{2}>0$,

$\left(\mathrm{A}_{3}\right) f$ is upper semicontinuous on $C$,

$\left(\mathrm{A}_{4}\right)$ For each $x \in C, f(x, \cdot)$ is convex and subdifferentiable on $C$,

$\left(\mathrm{A}_{5}\right) F \cap \operatorname{Sol}(f, C) \neq \emptyset$.

Under these assumptions, for each $r>0$ and $x \in C$, there exists a unique element $z \in C$ such that

$$
f(z, y)+\frac{1}{r}\langle y-z, z-x\rangle \geq 0 \quad \forall y \in C .
$$

Problem (1.1) is very general in the sense that it includes, as special cases, optimization problems, variational inequalities, minimax problems, equilibrium equilibriums, fixed point problems (see, e.g., [2-7]). Recently, it has become an attractive field for many researchers in both theory and its solution methods (see, e.g., [3, 4, 8-12] and the references therein). Most of these algorithms are based on inequality (1.2) for solving the underlying equilibrium problem when $F \cap \operatorname{Sol}(f, C) \neq \emptyset$. Motivated by this idea for finding a common point of $\operatorname{Sol}(f, C)$ and the fixed point set $\operatorname{Fix}(T)$ of a nonexpansive mapping $T$, Takahashi and Takahashi [13] first introduced an iterative scheme by the viscosity approximation method. The sequence $\left\{x^{n}\right\}$ is defined by

$$
\left\{\begin{array}{l}
x^{0} \in C, \\
f\left(u^{n}, y\right)+\frac{1}{r_{n}}\left\langle y-u^{n}, u^{n}-x^{n}\right\rangle \geq 0 \quad \forall y \in C, \\
x^{n+1}=\alpha_{n} g\left(x^{n}\right)+\left(1-\alpha_{n}\right) T\left(u^{n}\right) \quad \forall n \geq 0,
\end{array}\right.
$$

where $g: C \rightarrow C$ is contractive. Under certain conditions over the parameters $\left\{\alpha_{n}\right\}$ and $\left\{r_{n}\right\}$, they showed that the sequences $\left\{x^{n}\right\}$ and $\left\{u^{n}\right\}$ strongly converge to $z=$ $\operatorname{Pr}_{\mathrm{Fix}(T) \cap \operatorname{Sol}(f, C)} g(z)$, where $\operatorname{Pr}_{C}$ denotes the projection on $C$. At each iteration $n$ in all of 
these algorithms, it requires to solve approximation auxiliary equilibrium problems for finding a common solution of an equilibrium problem and a fixed point problem. In order to avoid this requirement, Anh [14] recently proposed a hybrid extragradient algorithm for finding a common point of the set $\operatorname{Fix}(T) \cap \operatorname{Sol}(f, C)$. Starting with an arbitrary initial point $x^{0} \in C$, iteration sequences are defined by

$$
\left\{\begin{array}{l}
y^{k}=\operatorname{argmin}\left\{\lambda_{k} f\left(x^{k}, y\right)+\frac{1}{2}\left\|y-x^{k}\right\|^{2}: y \in C\right\}, \\
t^{k}=\operatorname{argmin}\left\{\lambda_{k} f\left(y^{k}, t\right)+\frac{1}{2}\left\|t-x^{k}\right\|^{2}: t \in C\right\}, \\
x^{k+1}=\alpha_{k} x^{0}+\left(1-\alpha_{k}\right) T\left(x^{k}\right) .
\end{array}\right.
$$

Under certain conditions onto parameters $\left\{\lambda_{k}\right\}$ and $\left\{\alpha_{k}\right\}$, he showed that the sequences $\left\{x^{k}\right\},\left\{y^{k}\right\}$ and $\left\{t^{k}\right\}$ weakly converge to the point $x \in \operatorname{Fix}(T) \cap \operatorname{Sol}(f, C)$ in a real Hilbert space. At each main iteration $n$ of the scheme, he only solved strongly convex problems on $C$, but the proof of convergence was still done under the assumptions that $x^{n+1}-x^{n} \rightarrow 0$.

For finding a common point of a family of nonexpansive mappings $T_{i}(i \in \Gamma)$, as a corollary of Theorem 2.1 in [15], Zhou proposed the following iteration scheme:

$$
\left\{\begin{array}{l}
x^{0} \in \mathcal{H} \text { chosen arbitrarily, } \\
C_{1, i}=C, C_{1}=\bigcap_{i \in \Gamma} C_{1, i} \\
x^{1}=\operatorname{Pr}_{C_{1}}\left(x^{0}\right) \\
y^{n, i}=\left(1-\alpha_{n, i}\right) x^{n}+\alpha_{n, i} T_{i}\left(x^{n}\right) \\
C_{n+1, i}=\left\{z \in C_{n, i}: \alpha_{n, i}\left(1-2 \alpha_{n, i}\right)\left\|x^{n}-T_{i}\left(x^{n}\right)\right\|^{2} \leq\left\langle x^{n}-z, y^{n, i}-T_{i}\left(y^{n, i}\right)\right\rangle\right\} \\
C_{n+1}=\bigcap_{i \in \Gamma} C_{n+1, i} \\
x^{n+1}=\operatorname{Pr}_{C_{n+1}}\left(x^{0}\right)
\end{array}\right.
$$

Under the restrictions of the control sequences $0<\liminf _{n \rightarrow \infty} \alpha_{n, i} \leq \limsup _{n \rightarrow \infty} \alpha_{n, i} \leq$ $a_{i}<\frac{1}{2}$, he showed that the sequence $\left\{x^{n}\right\}$ defined by (1.4) strongly converges to $x^{*}=\operatorname{Pr}_{F}\left(x^{0}\right)$ in a real Hilbert space $\mathcal{H}$, where $F=\bigcap_{i \in \Gamma} \operatorname{Fix}\left(T_{i}\right)$.

In this paper, motivated by Ceng et al. [16, 17], Wang and Guo [18], Zhou [15], Nadezhkina and Takahashi [10], Cho et al. [19], Takahashi and Takahashi [13], Anh [6, 12] and Anh et al. $[20,21]$, we introduce several modified hybrid extragradient schemes to modify the iteration schemes (1.3) and (1.4) to obtain new strong convergence theorems for a family of nonexpansive mappings and the equilibrium problem $E P(f, C)$ in the framework of a real Hilbert space $\mathcal{H}$.

To investigate the convergence of this scheme, we recall the following technical lemmas which will be used in the sequel.

Lemma 1.1 ([14], Lemma 3.1) Let $C$ be a nonempty closed convex subset of a real Hilbert space $\mathcal{H}$. Let $f: C \times C \rightarrow \mathcal{R}$ be a pseudomonotone and Lipschitz-type continuous bifunction. For each $x \in C$, let $f(x, \cdot)$ be convex and subdifferentiable on $C$. Suppose that the sequences $\left\{x^{n}\right\},\left\{y^{n}\right\},\left\{t^{n}\right\}$ are generated by scheme (1.3) and $x^{*} \in \operatorname{Sol}(f, C)$. Then

$$
\left\|t^{n}-x^{*}\right\|^{2} \leq\left\|x^{n}-x^{*}\right\|^{2}-\left(1-2 \lambda_{n} c_{1}\right)\left\|x^{n}-y^{n}\right\|^{2}-\left(1-2 \lambda_{n} c_{2}\right)\left\|y^{n}-t^{n}\right\|^{2} \quad \forall n \geq 0 .
$$


Lemma 1.2 Let $C$ be a closed convex subset of a real Hilbert space $\mathcal{H}$, and let $\operatorname{Pr}_{C}$ be the metric projection from $\mathcal{H}$ on to $C$ (i.e., for $x \in \mathcal{H}, \operatorname{Pr}_{C}$ is the only point in $C$ such that $\| x-$ $\left.\operatorname{Pr}_{C} x \|=\inf \{\|x-z\|: z \in C\}\right)$. Given $x \in \mathcal{H}$ and $z \in C$. Then $z=\operatorname{Pr}_{C} x$ if only if there holds the relation $\langle x-z, y-z\rangle \leq 0$ for all $y \in C$.

Lemma 1.3 Let $\mathcal{H}$ be a real Hilbert space. Then the following equations hold:

(i) $\|x-y\|^{2}=\|x\|^{2}-\|y\|^{2}-2\langle x-y, y\rangle$ for all $x, y \in \mathcal{H}$.

(ii) $\|t x+(1-t) y\|^{2}=t\|x\|^{2}+(1-t)\|y\|^{2}-t(1-t)\|x-y\|^{2}$ for all $t \in[0,1]$ and $x, y \in \mathcal{H}$.

\section{Convergence theorems}

Now, we prove the main convergence theorem.

Theorem 2.1 Let $C$ be a nonempty closed convex subset of a real Hilbert space $\mathcal{H}$. Suppose that assumptions $\left(\mathrm{A}_{1}\right)-\left(\mathrm{A}_{5}\right)$ are satisfied and $\left\{T_{i}\right\}_{i \in \Gamma}$ is a family of nonexpansive mappings from $C$ into itself and a nonempty common fixed points set $F$. Let $\left\{x^{n}\right\}$ be a sequence generated by the following scheme:

$$
\left\{\begin{array}{l}
x^{0} \in \mathcal{H} \text { chosen arbitrarily, } \\
C_{1, i}=D_{1, i}=C, C_{1}=\bigcap_{i \in \Gamma} C_{1, i}, D_{1}=\bigcap_{i \in \Gamma} D_{1, i}, \\
x^{1}=\operatorname{Pr}_{C_{1} \cap D_{1}} x^{0} \\
y^{n}=\operatorname{argmin}\left\{\lambda_{n} f\left(x^{n}, y\right)+\frac{1}{2}\left\|y-x^{n}\right\|^{2}: y \in C\right\}, \\
z^{n}=\operatorname{argmin}\left\{\lambda_{n} f\left(y^{n}, y\right)+\frac{1}{2}\left\|z-x^{n}\right\|^{2}: z \in C\right\}, \\
y^{n, i}=\left(1-\alpha_{n, i}\right) z^{n}+\alpha_{n, i} T_{i} z^{n}, \\
C_{n+1, i}=\left\{z \in C_{n, i}: \alpha_{n, i}\left(1-2 \alpha_{n, i}\right)\left\|z^{n}-T_{i} z^{n}\right\|^{2} \leq\left\langle z^{n}-z, y^{n, i}-T_{i} y^{n, i}\right\rangle\right\}, \\
C_{n+1}=\bigcap_{i \in \Gamma} C_{n+1, i}, \\
D_{n+1, i}=\left\{z \in D_{n, i}:\left\|y^{n, i}-z\right\| \leq\left\|x^{n}-z\right\|\right\}, \\
D_{n+1}=\bigcap_{i \in \Gamma} D_{n+1, i}, \\
x^{n+1}=\operatorname{Pr}_{C_{n+1} \cap D_{n+1}} x^{0}, \\
0<\liminf \alpha_{n, i} \leq \lim \sup \alpha_{n, i}<1, \\
\left\{\lambda_{n}\right\} \subset[a, b] \text { for some } a, b \in\left(0, \frac{1}{L}\right), \text { where } L=\max \left\{2 c_{1}, 2 c_{2}\right\} .
\end{array}\right.
$$

Then the sequences $\left\{x^{n}\right\},\left\{y^{n}\right\}$ and $\left\{z^{n}\right\}$ strongly converge to the same point $\operatorname{Pr}_{F \cap \operatorname{Sol}(f, C)} x^{0}$.

Proof The proof of this theorem is divided into several steps.

Step 1. Claim that $C_{n}$ and $D_{n}$ are closed and convex for all $n \geq 0$.

We have to show that for any fixed point but arbitrary $i \in \Gamma, C_{n, i}$ is closed and convex for every $n \geq 0$. This can be proved by induction on $n$. It is obvious that $C_{1, i}=C$ is closed and convex. Assume that $C_{n, i}$ is closed and convex for some $n \in \mathcal{N}^{*}=\{1,2, \ldots\}$. We have that the set

$$
A=\left\{z \in C: \alpha_{n, i}\left(1-2 \alpha_{n, i}\right)\left\|z^{n}-T_{i} z^{n}\right\|^{2} \leq\left\langle z^{n}-z, y^{n, i}-T_{i} y^{n, i}\right\rangle\right\}
$$


is closed and convex, and $C_{n+1, i}=C_{n, i} \cap A$, hence $C_{n+1, i}$ is closed and convex. Then $C_{n}$ is closed and convex for all $n \geq 0$. We can write $D_{n+1, i}$ under the form

$$
D_{n+1, i}=\left\{z \in D_{n, i}:\left\|y^{n, i}-x^{n}\right\|^{2}+2\left\langle y^{n, i}-x^{n}, x^{n}-z\right\rangle \leq 0\right\} .
$$

Then $D_{n+1, i}$ is closed and convex. Thus, $D_{n}$ is closed and convex.

Step 2. Claim that $F \cap \operatorname{Sol}(f, C) \subseteq C_{n} \cap D_{n}$ for all $n \in \mathcal{N}^{*}$.

First, we show that $F \subseteq C_{n}$ by induction on $n$. It suffices to show that $F \subseteq C_{n, i}$.

We have $F \subseteq C=C_{1, i}$ is obvious. Suppose $F \subseteq C_{n, i}$ for some $n \in \mathcal{N}$. We have to show that $F \subseteq C_{n+1, i}$. Indeed, let $w \in F$, by inductive hypothesis, we have $w \in C_{n, i}$ and

$$
\begin{aligned}
\left\|z^{n}-T_{i} z^{n}\right\|^{2}= & \left\langle z^{n}-T_{i} z^{n}, z^{n}-T_{i} z^{n}\right\rangle \\
= & \frac{1}{\alpha_{n, i}}\left\langle z^{n}-y^{n, i}, z^{n}-T_{i} z^{n}\right\rangle \\
= & \frac{1}{\alpha_{n, i}}\left\langle z^{n}-y^{n, i}, z^{n}-T_{i} z^{n}-\left(y^{n, i}-T_{i} y^{n, i}\right)\right\rangle+\frac{1}{\alpha_{n, i}}\left\langle z^{n}-y^{n, i}, y^{n, i}-T_{i} y^{n, i}\right\rangle \\
= & \frac{1}{\alpha_{n, i}}\left\langle z^{n}-y^{n, i}, z^{n}-T_{i} z^{n}-\left(y^{n, i}-T_{i} y^{n, i}\right)\right\rangle \\
& +\frac{1}{\alpha_{n, i}}\left\langle z^{n}-w+w-y^{n, i}, y^{n, i}-T_{i} y^{n, i}\right\rangle \\
= & \frac{1}{\alpha_{n, i}}\left\langle z^{n}-y^{n, i}, z^{n}-y^{n, i}\right\rangle+\frac{1}{\alpha_{n, i}}\left\langle z^{n}-y^{n, i}, T_{i} y^{n, i}-T_{i} z^{n}\right\rangle \\
& +\frac{1}{\alpha_{n, i}}\left\langle z^{n}-w, y^{n, i}-T_{i} y^{n, i}\right\rangle+\frac{1}{\alpha_{n, i}}\left\langle w-y^{n, i}, y^{n, i}-T_{i} y^{n, i}\right\rangle \\
\leq & \frac{2}{\alpha_{n, i}}\left\|z^{n}-y^{n, i}\right\|^{2}+\frac{1}{\alpha_{n, i}}\left\langle z^{n}-w, y^{n, i}-T_{i} y^{n, i}\right\rangle \\
& +\frac{1}{\alpha_{n, i}}\left\langle w-y^{n, i}, y^{n, i}-T_{i} y^{n, i}\right\rangle .
\end{aligned}
$$

On the other hand, for all $w \in F$ and $y^{n, i} \in C$, we have

$$
\begin{aligned}
\left\|w-y^{n, i}\right\|^{2} & \geq\left\langle T_{i} w-T_{i} y^{n, i}, w-y^{n, i}\right\rangle \\
& =\left\langle w-T_{i} y^{n, i}, w-y^{n, i}\right\rangle \\
& =\left\langle w-y^{n, i}+y^{n, i}-T_{i} y^{n, i}, w-y^{n, i}\right\rangle \\
& =\left\|w-y^{n, i}\right\|^{2}+\left\langle y^{n, i}-T_{i} y^{n, i}, w-y^{n, i}\right\rangle,
\end{aligned}
$$

and hence

$$
\left\langle w-y^{n, i}, y^{n, i}-T_{i} y^{n, i}\right\rangle \leq 0 .
$$

Combining this with (2.1), we obtain

$$
\begin{aligned}
\left\|z^{n}-T_{i} z^{n}\right\|^{2} & \leq \frac{2}{\alpha_{n, i}}\left\|z^{n}-y^{n, i}\right\|^{2}+\frac{1}{\alpha_{n, i}}\left\langle z^{n}-w, y^{n, i}-T_{i} y^{n, i}\right\rangle \\
& \leq 2 \alpha_{n, i}\left\|z^{n}-T_{i} z^{n}\right\|^{2}+\frac{1}{\alpha_{n, i}}\left\langle z^{n}-w, y^{n, i}-T_{i} y^{n, i}\right\rangle .
\end{aligned}
$$


This follows that

$$
\alpha_{n, i}\left(1-2 \alpha_{n, i}\right)\left\|z^{n}-T_{i} z^{n}\right\|^{2} \leq\left\langle z^{n}-w, y^{n, i}-T_{i} y^{n, i}\right\rangle .
$$

By the definition of $C_{n+1, i}$, we have $w \in C_{n+1, i}$, and so $F \subseteq C_{n+1, i}$ for all $i \in \Gamma$, which deduces that $F \subseteq C_{n}$. This shows that $F \cap \operatorname{Sol}(f, C) \subseteq C_{n}$ for all $n \in \mathcal{N}^{*}$.

Next, we will prove $F \cap \operatorname{Sol}(f, C) \subseteq D_{n}$ by induction on $n \in \mathcal{N}^{*}$. It suffices to show that $F \cap$ $\operatorname{Sol}(f, C) \subseteq D_{n, i}$. Indeed, $F \subseteq C=D_{1, i}$ so $F \cap \operatorname{Sol}(f, C) \subseteq D_{1, i}$. Suppose that $F \cap \operatorname{Sol}(f, C) \subseteq$ $D_{n, i}$. Let $x^{*} \in F \cap \operatorname{Sol}(f, C)$, then $x^{*} \in D_{n, i}$. Using Lemma 1.1, we get

$$
\begin{aligned}
\left\|y^{n, i}-x^{*}\right\|^{2} & =\left\|\left(1-\alpha_{n, i}\right) z^{n}+\alpha_{n, i} T_{i} z^{n}-x^{*}\right\|^{2} \\
& \leq\left(1-\alpha_{n, i}\right)\left\|z^{n}-x^{*}\right\|^{2}+\alpha_{n, i}\left\|T_{i} z^{n}-T_{i} x^{*}\right\|^{2} \\
& \leq\left\|z^{n}-x^{*}\right\|^{2} \\
& \leq\left\|x^{n}-x^{*}\right\|^{2}-\left(1-2 \lambda_{n} c_{1}\right)\left\|x^{n}-y^{n}\right\|^{2}-\left(1-2 \lambda_{n} c_{2}\right)\left\|y^{n}-z^{n}\right\|^{2} \\
& \leq\left\|x^{n}-x^{*}\right\|^{2} .
\end{aligned}
$$

Then we have $x^{*} \in D_{n+1, i}$ and hence $F \cap \operatorname{Sol}(f, C) \subseteq D_{n+1, i}$. This shows that $F \cap \operatorname{Sol}(f, C) \subseteq$ $D_{n}$, which yields that $F \cap \operatorname{Sol}(f, C) \subseteq C_{n} \cap D_{n}$ for all $n \in \mathcal{N}^{*}$.

Step 3. Claim that the sequence $\left\{x^{n}\right\}$ is bounded and there exists the $\operatorname{limit}_{\lim } \rightarrow \infty \| x^{n}-$ $x^{0} \|=c$.

From $x^{n}=\operatorname{Pr}_{C_{n} \cap D_{n}} x^{0}$, it follows that

$$
\left\langle x^{0}-x^{n}, x^{n}-y\right\rangle \geq 0 \quad \forall y \in C_{n} \cap D_{n} .
$$

Then, using Step 2, we have $F \cap \operatorname{Sol}(f, C) \subseteq C_{n} \cap D_{n}$ and

$$
\left\langle x^{0}-x^{n}, x^{n}-w\right\rangle \geq 0 \quad \forall w \in F \cap \operatorname{Sol}(f, C) .
$$

Combining this and assumption $\left(\mathrm{A}_{5}\right)$, the projection $\operatorname{Pr}_{F \cap \operatorname{Sol}(f, C)} x^{0}$ is well defined and there exits a unique point $p$ such that $p=\operatorname{Pr}_{F \cap \operatorname{Sol}(f, C)} x^{0}$. So, we have

$$
\begin{aligned}
0 & \leq\left\langle x^{0}-x^{n}, x^{n}-p\right\rangle=\left\langle x^{0}-x^{n}, x^{n}-x^{0}+x^{0}-p\right\rangle \\
& \leq-\left\|x^{0}-x^{n}\right\|^{2}+\left\|x^{0}-x^{n}\right\|\left\|x^{0}-p\right\|,
\end{aligned}
$$

and hence

$$
\left\|x^{0}-x^{n}\right\| \leq\left\|x^{0}-p\right\|
$$

Then the sequence $\left\{x^{n}\right\}$ is bounded. So, the sequences $\left\{y^{n}\right\},\left\{z^{n}\right\},\left\{y^{n, i}\right\},\left\{T_{i} y^{n, i}\right\}$ also are bounded. Since $x^{n+1} \in C_{n+1} \cap D_{n+1} \subset C_{n} \cap D_{n}$ and (2.3), we have

$$
\begin{aligned}
0 & \leq\left\langle x^{0}-x^{n}, x^{n}-x^{n+1}\right\rangle=\left\langle x^{0}-x^{n}, x^{n}-x^{0}+x^{0}-x^{n+1}\right\rangle \\
& \leq-\left\|x^{0}-x^{n}\right\|^{2}+\left\|x^{0}-x^{n}\right\|\left\|x^{0}-x^{n+1}\right\|,
\end{aligned}
$$


and hence $\left\|x^{0}-x^{n}\right\| \leq\left\|x^{0}-x^{n+1}\right\|$. This together with the boundedness of $\left\{x^{n}\right\}$ implies that the limit $\lim _{n \rightarrow \infty}\left\|x^{n}-x^{0}\right\|=c$ exists.

Step 4. We claim that $\lim _{n \rightarrow \infty} x^{n}=q \in C$.

Since $C_{m} \cap D_{m} \subseteq C_{n} \cap D_{n}, x^{m}=\operatorname{Pr}_{C_{m} \cap D_{m}} x^{0} \in C_{n} \cap D_{n}$ for any positive integer $m \geq n$ and (2.3), we have

$$
\left\langle x^{0}-x^{n}, x^{n}-x^{n+m}\right\rangle \geq 0 .
$$

Then

$$
\begin{aligned}
\left\|x^{n}-x^{n+m}\right\|^{2} & =\left\|x^{n}-x^{0}+x^{0}-x^{n+m}\right\|^{2} \\
& =\left\|x^{n}-x^{0}\right\|^{2}+\left\|x^{0}-x^{n+m}\right\|^{2}-2\left\langle x^{0}-x^{n}, x^{0}-x^{n+m}\right\rangle \\
& \leq\left\|x^{0}-x^{n+m}\right\|^{2}-\left\|x^{n}-x^{0}\right\|^{2}-2\left\langle x^{0}-x^{n}, x^{n}-x^{n+m}\right\rangle \\
& \leq\left\|x^{0}-x^{n+m}\right\|^{2}-\left\|x^{n}-x^{0}\right\|^{2} .
\end{aligned}
$$

Passing the limit in (2.5) as $n \rightarrow \infty$, we get $\lim _{n \rightarrow \infty}\left\|x^{n}-x^{n+m}\right\|=0 \forall m \in \mathcal{N}^{*}$. Hence, $\left\{x^{n}\right\}$ is a Cauchy sequence in a real Hilbert space $\mathcal{H}$ and so $\lim _{n \rightarrow \infty} x^{n}=q \in C$.

Step 5. We claim that $q=\operatorname{Pr}_{F \cap \operatorname{Sol}(f, C)} x^{0}$, where $q=\lim _{n \rightarrow \infty} x^{n}$.

First we show that $q \in F \cap \operatorname{Sol}(f, C)$. Since $x^{n+1}=\operatorname{Pr}_{C_{n+1} \cap D_{n+1}} x^{0}$, we have $x^{n+1} \in D_{n+1}$. Then $x^{n+1} \in D_{n+1, i}$ and

$$
\left\|y^{n, i}-x^{n+1}\right\| \leq\left\|x^{n}-x^{n+1}\right\|,
$$

which yields that

$$
\begin{aligned}
\left\|x^{n}-y^{n, i}\right\| & \leq\left\|x^{n}-x^{n+1}\right\|+\left\|x^{n+1}-y^{n, i}\right\| \\
& \leq 2\left\|x^{n}-x^{n+1}\right\| .
\end{aligned}
$$

Combining this and $\lim _{n \rightarrow \infty}\left\|x^{n}-x^{m}\right\|=0$ for all $m \in \mathcal{N}^{*}$, we get

$$
\lim _{n \rightarrow \infty}\left\|x^{n}-y^{n, i}\right\|=0
$$

For each $x^{*} \in \operatorname{Sol}(f, C) \cap F$, by (2.2) we have

$$
\begin{aligned}
\left(1-2 b c_{1}\right)\left\|x^{n}-y^{n}\right\|^{2} & \leq\left(1-2 \lambda_{n} c_{1}\right)\left\|x^{n}-y^{n}\right\|^{2} \\
& \leq\left\|x^{n}-x^{*}\right\|^{2}-\left\|y^{n, i}-x^{*}\right\|^{2} \\
& =\left(\left\|x^{n}-x^{*}\right\|+\left\|y^{n, i}-x^{*}\right\|\right)\left(\left\|x^{n}-x^{*}\right\|-\left\|y^{n, i}-x^{*}\right\|\right) \\
& \leq\left(\left\|x^{n}-x^{*}\right\|+\left\|y^{n, i}-x^{*}\right\|\right)\left(\left\|x^{n}-y^{n, i}\right\|\right) .
\end{aligned}
$$

Using this, the boundedness of sequences $\left\{x^{n}\right\},\left\{y^{n, i}\right\}$ and (2.6), we obtain

$$
\lim _{n \rightarrow \infty}\left\|x^{n}-y^{n}\right\|=0
$$


By a similar way, we also have $\lim _{n \rightarrow \infty}\left\|z^{n}-y^{n}\right\|=0$. Then it follows from the inequality

$$
\left\|x^{n}-z^{n}\right\| \leq\left\|x^{n}-y^{n}\right\|+\left\|y^{n}-z^{n}\right\|
$$

that

$$
\lim _{n \rightarrow \infty}\left\|x^{n}-z^{n}\right\|=0
$$

On the other hand, we have

$$
\left\|y^{n, i}-z^{n}\right\| \leq\left\|y^{n, i}-x^{n}\right\|+\left\|x^{n}-z^{n}\right\| .
$$

Combining this, (2.6) and (2.8), we obtain $\lim _{n \rightarrow \infty}\left\|y^{n, i}-z^{n}\right\|=0$. By the definition of the sequence $\left\{y^{n, i}\right\}$, we have

$$
\left\|y^{n, i}-z^{n}\right\|=\alpha_{n, i}\left\|T_{i} z^{n}-z^{n}\right\|,
$$

and hence

$$
\lim _{n \rightarrow \infty}\left\|T_{i} z^{n}-z^{n}\right\|=0,
$$

which yields that

$$
\begin{aligned}
\left\|T_{i} x^{n}-x^{n}\right\| & \leq\left\|T_{i} x^{n}-T_{i} z^{n}\right\|+\left\|T_{i} z^{n}-z^{n}\right\|+\left\|x^{n}-z^{n}\right\| \\
& \leq 2\left\|x^{n}-z^{n}\right\|+\left\|T_{i} z^{n}-z^{n}\right\| \\
& \rightarrow 0 \quad \text { as } n \rightarrow \infty
\end{aligned}
$$

and

$$
\lim _{n \rightarrow \infty}\left\|T_{i} x^{n}-x^{n}\right\|=0
$$

It follows from Step 4 that $\lim _{n \rightarrow \infty} T_{i} x^{n}=q$. Hence $q \in F$.

Now we show that $q \in \operatorname{Sol}(f, C)$. By Step 5 , we have $y^{n} \rightarrow q$ as $n \rightarrow \infty$.

Since $y^{n}$ is the unique solution of the strongly convex problem

$$
\min \left\{\frac{1}{2}\left\|y-x^{n}\right\|^{2}+\lambda_{n} f\left(x^{n}, y\right): y \in C\right\},
$$

we get

$$
0 \in \partial_{2}\left(\lambda_{n} f\left(x^{n}, y\right)+\frac{1}{2}\left\|y-x^{n}\right\|^{2}\right)\left(y^{n}\right)+N_{C}\left(y^{n}\right) .
$$

From this it follows that

$$
0=\lambda_{n} w+y^{n}-x^{n}+\bar{w},
$$


where $w \in \partial_{2} f\left(x^{n}, \cdot\right)\left(y^{n}\right)$ and $\bar{w} \in N_{C}\left(y^{n}\right)$. By the definition of the normal cone $N_{C}$, we have

$$
\left\langle y^{n}-x^{n}, y-y^{n}\right\rangle \geq \lambda_{n}\left\langle w, y^{n}-y\right\rangle \quad \forall y \in C .
$$

On the other hand, since $f\left(x^{n}, \cdot\right)$ is subdifferentiable on $C$, by the well-known MoreauRockafellar theorem, there exists $w \in \partial_{2} f\left(x^{n}, \cdot\right)\left(y^{n}\right)$ such that

$$
f\left(x^{n}, y\right)-f\left(x^{n}, y^{n}\right) \geq\left\langle w, y-y^{n}\right\rangle \quad \forall y \in C .
$$

Combining this with (2.9), we have

$$
\lambda_{n}\left(f\left(x^{n}, y\right)-f\left(x^{n}, y^{n}\right)\right) \geq\left\langle y^{n}-x^{n}, y^{n}-y\right\rangle \quad \forall y \in C .
$$

Then, using $\left\{\lambda_{n}\right\} \subset[a, b] \subset\left(0, \frac{1}{L}\right),(2.7), x^{n} \rightarrow q, y^{n} \rightarrow q$ as $n \rightarrow \infty$ and the upper semicontinuity of $f$, we have

$$
f(q, y) \geq 0 \quad \forall q \in C
$$

This means that $q \in \operatorname{Sol}(f, C)$. By taking the limit in (2.4), we have

$$
\left\langle x^{0}-q, q-w\right\rangle \geq 0 \quad \forall w \in F \cap \operatorname{Sol}(f, C),
$$

which implies that $q=\operatorname{Pr}_{F \cap \operatorname{Sol}(f, C)} x^{0}$. Thus, the subsequences $\left\{x^{n}\right\},\left\{y^{n}\right\},\left\{z^{n}\right\}$ strongly converge to the same point $q=\operatorname{Pr}_{F \cap \operatorname{Sol}(f, C)} x^{0}$. This completes the proof.

Now, notice that $\forall w \in F$

$$
\begin{aligned}
\left\|z^{n}-T_{i} z^{n}\right\|^{2} & =\left\|z^{n}-w+w-T_{i} z^{n}\right\|^{2} \\
& =\left\|z^{n}-w\right\|^{2}+\left\|w-T_{i} z^{n}\right\|^{2}+2\left\langle z^{n}-w, w-T_{i} z^{n}\right\rangle \\
& \leq 2\left\|z^{n}-w\right\|^{2}+2\left\langle z^{n}-w, w-z^{n}+z^{n}-T_{i} z^{n}\right\rangle \\
& =2\left\|z^{n}-w\right\|^{2}-2\left\|z^{n}-w\right\|^{2}+2\left\langle z^{n}-w, z^{n}-T_{i} z^{n}\right\rangle \\
& =2\left\langle z^{n}-w, z^{n}-T_{i} z^{n}\right\rangle .
\end{aligned}
$$

Hence

$$
\begin{aligned}
\left\|y^{n, i}-w\right\|^{2}= & \left\|\left(1-\alpha_{n, i}\right)\left(z^{n}-w\right)+\alpha_{n, i}\left(T_{i} z^{n}-w\right)\right\|^{2} \\
= & \left(1-\alpha_{n, i}\right)\left\|z^{n}-w\right\|^{2}+\alpha_{n, i}\left\|T_{i} z^{n}-w\right\|^{2}-\alpha_{n, i}\left(1-\alpha_{n, i}\right)\left\|T_{i} z^{n}-z^{n}\right\|^{2} \\
= & \left(1-\alpha_{n, i}\right)\left\|z^{n}-w\right\|^{2}+\alpha_{n, i}\left\|T_{i} z^{n}-z^{n}+z^{n}-w\right\|^{2} \\
& -\alpha_{n, i}\left(1-\alpha_{n, i}\right)\left\|T_{i} z^{n}-z^{n}\right\|^{2} \\
= & \left(1-\alpha_{n, i}\right)\left\|z^{n}-w\right\|^{2}+\alpha_{n, i}\left\|T_{i} z^{n}-z^{n}\right\|^{2}+\alpha_{n, i}\left\|z^{n}-w\right\|^{2} \\
& +2 \alpha_{n, i}\left(T_{i} z^{n}-z^{n}, z^{n}-w\right\rangle-\alpha_{n, i}\left(1-\alpha_{n, i}\right)\left\|T_{i} z^{n}-z^{n}\right\|^{2} \\
\leq & \left\|z^{n}-w\right\|^{2}+2 \alpha_{n, i}\left(z^{n}-w, z^{n}-T_{i} z^{n}\right\rangle+2 \alpha_{n, i}\left(T_{i} z^{n}-z^{n}, z^{n}-w\right\rangle
\end{aligned}
$$




$$
\begin{aligned}
& -\alpha_{n, i}\left(1-\alpha_{n, i}\right)\left\|T_{i} z^{n}-z^{n}\right\|^{2} \\
= & \left\|z^{n}-w\right\|^{2}-\alpha_{n, i}\left(1-\alpha_{n, i}\right)\left\|T_{i} z^{n}-z^{n}\right\|^{2} .
\end{aligned}
$$

From (2.10) and using the methods in Theorem 2.1, we can get the following convergence result.

Theorem 2.2 Let $C$ be a nonempty closed convex subset of a real Hilbert space $\mathcal{H}$. Suppose that assumptions $\left(\mathrm{A}_{1}\right)-\left(\mathrm{A}_{5}\right)$ are satisfied and $\left\{T_{i}\right\}_{i \in \Gamma}$ is a family of nonexpansive mappings from $C$ into itself and a nonempty common fixed points set $F$. Let $\left\{x^{n}\right\}$ be a sequence generated by the following scheme:

$$
\left\{\begin{array}{l}
x^{0} \in \mathcal{H} \text { chosen arbitrarily, } \\
C_{1, i}=D_{1, i}=C, C_{1}=\bigcap_{i \in \Gamma} C_{1, i}, D_{1}=\bigcap_{i \in \Gamma} D_{1, i}, \\
x^{1}=\operatorname{Pr}_{C_{1} \cap D_{1}} x^{0} \\
y^{n}=\operatorname{argmin}\left\{\lambda_{n} f\left(x^{n}, y\right)+\frac{1}{2}\left\|y-x^{n}\right\|^{2}: y \in C\right\}, \\
z^{n}=\operatorname{argmin}\left\{\lambda_{n} f\left(y^{n}, y\right)+\frac{1}{2}\left\|z-x^{n}\right\|^{2}: z \in C\right\}, \\
y^{n, i}=\left(1-\alpha_{n, i}\right) z^{n}+\alpha_{n, i} T_{i} z^{n}, \\
C_{n+1, i}=\left\{z \in C_{n, i}:\left\|y^{n, i}-z\right\|^{2} \leq\left\|z^{n}-z\right\|^{2}-\alpha_{n, i}\left(1-\alpha_{n, i}\right)\left\|z^{n}-T_{i} z^{n}\right\|^{2}\right\}, \\
C_{n+1}=\bigcap_{i \in \Gamma} C_{n+1, i}, \\
D_{n+1, i}=\left\{z \in D_{n, i}:\left\|y^{n, i}-z\right\| \leq\left\|x^{n}-z\right\|\right\}, \\
D_{n+1}=\bigcap_{i \in \Gamma} D_{n+1, i}, \\
x^{n+1}=\operatorname{Pr}_{C_{n+1} \cap D_{n+1}} x^{0}, \\
0<\liminf \alpha_{n, i} \leq \lim \sup \alpha_{n, i}<1, \\
\left\{\lambda_{n}\right\} \subset[a, b] \text { for some } a, b \in\left(0, \frac{1}{L}\right), \text { where } L=\max \left\{2 c_{1}, 2 c_{2}\right\} .
\end{array}\right.
$$

Then the sequences $\left\{x^{n}\right\},\left\{y^{n}\right\}$ and $\left\{z^{n}\right\}$ converge strongly to the same point $\operatorname{Pr}_{F \cap \operatorname{Sol}(f, C)} x^{0}$.

\section{Competing interests}

The author declares that he has no competing interests.

Received: 7 May 2014 Accepted: 10 September 2014 Published: 25 Sep 2014

\section{References}

1. Mastroeni, G: Gap function for equilibrium problems. J. Glob. Optim. 27, 411-426 (2004)

2. Zeng, LC, Ansari, QH, Schaible, S, Yao, J-C: Iterative methods for generalized equilibrium problems, systems of general generalized equilibrium problems and fixed point problems for nonexpansive mappings in Hilbert spaces. Fixed Point Theory 12(2), 293-308 (2011)

3. Peng, JW: Iterative algorithms for mixed equilibrium problems, strict pseudocontractions and monotone mappings. J. Optim. Theory Appl. 144, 107-119 (2010)

4. Yao, Y, Liou, YC, Wu, YJ: An extragradient method for mixed equilibrium problems and fixed point problems. Fixed Point Theory Appl. 2009, Article ID 632819 (2009)

5. Blum, E, Oettli, W: From optimization and variational inequality to equilibrium problems. Math. Stud. 63, 127-149 (1994)

6. Anh, PN: A hybrid extragradient method for pseudomonotone equilibrium problems and fixed point problems. Bull. Malays. Math. Soc. 36, 107-116 (2013)

7. Anh, PN, Kim, JK: Outer approximation algorithms for pseudomonotone equilibrium problems. Comput. Math. Appl. 61, 2588-2595 (2011)

8. Ceng, LC, Ansari, QH, Yao, JC: Hybrid proximal-type and hybrid shrinking projection algorithms for equilibrium problems, maximal monotone operators and relatively nonexpansive mappings. Numer. Funct. Anal. Optim. 31(7), 763-797 (2010) 
9. Zeng, LC, Al-Homidan, S, Ansari, QH: Hybrid proximal-type algorithms for generalized equilibrium problems, maximal monotone operators and relatively nonexpansive mappings. Fixed Point Theory Appl. 2011, Article ID 973028 (2011)

10. Nadezhkina, N, Takahashi, W: Weak convergence theorem by an extragradient method for nonexpansive mappings and monotone mappings. J. Optim. Theory Appl. 128, 191-201 (2006)

11. Sun, S: An alternative regularization method for equilibrium problems and fixed point of nonexpansive mappings. J. Appl. Math. 2012, Article ID 202860 (2012). doi:10.1155/2012/202860

12. Anh, PN: Strong convergence theorems for nonexpansive mappings and Ky Fan inequalities. J. Optim. Theory Appl. $154,303-320(2012)$

13. Takahashi, S, Takahashi, W: Viscosity approximation methods for equilibrium problems and fixed point problems in Hilbert spaces. J. Math. Anal. Appl. 331, 506-515 (2007)

14. Anh, PN: A hybrid extragradient method extended to fixed point problems and equilibrium problems. Optimization 62, 271-283 (2013)

15. Zhou, $\mathrm{H}$ : Strong convergence theorems for a family of Lipschitz quasi-pseudo-contractions in Hilbert spaces. Nonlinear Anal. 71, 120-125 (2009)

16. Ceng, LC, Ansari, QH, Schaible, S: Hybrid extragradient-like methods for generalized mixed equilibrium problems, systems of generalized equilibrium problems and optimization problems. J. Glob. Optim. 53(1), 69-96 (2012)

17. Ceng, LC, Ansari, QH, Yao, JC: Hybrid pseudoviscosity approximation schemes for equilibrium problems and fixed point problems of infinitely many nonexpansive mappings. Nonlinear Anal. Hybrid Syst. 4(4), 743-754 (2010)

18. Wang, S, Guo, B: New iterative scheme with nonexpansive mappings for equilibrium problems and variational inequality problems in Hilbert spaces. J. Comput. Appl. Math. 233, 2620-2630 (2010)

19. Cho, YJ, Argyros, IK, Petrot, N: Approximation methods for common solutions of generalized equilibrium, systems of nonlinear variational inequalities and fixed point problems. Comput. Math. Appl. 60, 2292-2301 (2010)

20. Anh, PN, Kim, JK, Nam, JM: Strong convergence of an extragradient method for equilibrium problems and fixed point problems. J. Korean Math. Soc. 49, 187-200 (2012)

21. Anh, PN, Son, DX: A new iterative scheme for pseudomonotone equilibrium problems and a finite family of pseudocontractions. J. Appl. Math. Inform. 29, 1179-1191 (2011)

10.1186/1687-1812-2014-200

Cite this article as: Thanh: Strong convergence theorems for equilibrium problems involving a family of nonexpansive mappings. Fixed Point Theory and Applications 2014, 2014:200

\section{Submit your manuscript to a SpringerOpen ${ }^{\ominus}$ journal and benefit from:}

- Convenient online submission

- Rigorous peer review

- Immediate publication on acceptance

- Open access: articles freely available online

- High visibility within the field

- Retaining the copyright to your article 